\title{
A Novel LR-QPSO Algorithm for Profit Maximization of GENCOs in Deregulated Power System
}

\author{
K. Asokan \\ Assistant professor \\ Department of Electrical Engg \\ Annamalai University \\ Annamalai Nagar, India
}

\author{
R. Ashok Kumar \\ Professor \\ Department of Electrical Engg \\ Annamalai University \\ Annamalai Nagar, India
}

\begin{abstract}
The electric power industry need changes in various power system operation, control and planning activities. Generation companies (GENCOs) schedule their generators with an objective to maximize their own profit rather than compromising on social benefit. Power and reserve prices become important factors in decision process. GENCOs decision to commit generating units is associated with financial risks. This paper presents a hybrid model between Lagrangian Relaxation (LR) and Quantum inspired Particle Swarm Optimization (QPSO), to solve the profit-based unit commitment problem. The proposed approach is investigated on three unit and ten unit test systems and numerical results are tabulated. Simulation results shows that this approach effectively maximize the GENCO's profit when compared with existing methods.
\end{abstract}

\section{Keywords}

Electricity markets, Generation company (GENCO), Independent system operator (ISO), profit based unit commitment (PBUC), profit maximization, LR-QPSO method.

\section{INTRODUCTION}

Profit Based Unit Commitment (PBUC) problem is one of the important optimization problems in power system operation under deregulated environment [1]. Earlier, the power generation was dominated by vertically integrated electric utilities (VIEU) that owned most of the generation, transmission and distribution sub-systems. Recently, most of the electric power utilities are unbundling these sub-systems as part of deregulation process. Deregulation [2] is unbundling of vertically integrated power system into generation (GENCOs), transmission (TRANSCOs) and distribution (DISCOs) companies. The basic aim of deregulation is to create competition among generating companies and to provide different choice of generation options at cheaper price to consumers. The objective of GENCOs is the maximization of their profit, so the problem of UC needs to be termed differently as Profit Based Unit Commitment (PBUC). The PBUC problem is divided into two sub problems [3-4]. The first sub-problem is the determination of status of the generating units and second sub-problem is the determination of output powers of committed units.

Earlier, classical methods such as [5-11] Priority List (PL), Dynamic Programming (DP), Branch- Bound, Mixed Integer
Programming (MIP) and Lagrangian relaxation (LR) were used to solve the UC problem. Among these methods, the Priority List method [6] is a simple method but the quality of solution is rough. The Dynamic Programming [7] is a flexible method to solve the UC problem. This approach features the classification of generating units into related groups so as to minimize the number of unit combinations which must be tested without precluding the optimal path. The dynamic programming technique involves huge computational time to obtain the solution because of its complex dimensionality with large number of generating units. Another approach has been presented for solving the unit commitment problem based on branch and bound techniques [8]. The method incorporates time-dependent start-up costs, demand and reserve constraints, and minimum up and down time constraints. The priority ordering of the units is not necessary in this technique.

Lagrange Relaxation method [11] provides fast solution but sometimes it suffers from numerical convergence problem especially when the problem is nonconvex. Besides, this method strongly depends on the technique used to update Lagrange multipliers. Many researchers dealing with LR are using sub gradient technique for solving this problem. Even though, the solution obtained from gradient-based method suffers from convergence problem and always gets stuck into a local optimum. In order to overcome these problems, many stochastic optimizations such as genetic algorithm [12-13], Memetic algorithm [14], Ant colony optimization [15], Particle swarm optimization [16-17] and Muller method [1819] were introduced into power system optimization. These methods begin with a population of starting points, use only the objective function information, and search a solution in parallel using operators borrowed from natural biology. These methods are seems to be fast and reliable, but it has a problem of convergence on large scale power system problem. Hybrid methods such as LR-MIP [20], LR-GA [21] and LR-EP [2223 ] have been used for solving the PBUC problems.

In this paper, a novel hybrid method between Lagrangian relaxation (LR) and Quantum inspired Particle Swarm Optimization (QPSO) is used as a Ton $_{i} \geq$ Tup $_{i}$, Toff $_{i} \geq$ Tdown $_{i}$ tool for solving PBUC optimization problem. The proposed approach has been tested on three units 12 hour and ten units 24 hour test system and numerical results are tabulated. This results show that this method effectively maximizes the GENCOs profit compared with conventional methods. The proposed method helps GENCOs to decide how much power and reserve should be sold into energy and ancillary power markets respectively. 


\section{PROBLEM FORMULATION}

The objective is to determine the generating unit schedules for maximizing the profit of Generation Companies subject to all prevailing constraint such as load demand, spinning reserve and market prices. The term profit is defined as the difference between revenue obtained from sale of energy with market price and total operating cost of the generating company.

The PBUC can be mathematically formulated by the following equations.

$$
\begin{gathered}
\text { Maximize } P F=R V-T C \\
\text { or } \\
T C-R V
\end{gathered}
$$

The spot power price and reserve power price decisions are made based on the reserve payments made. Researchers have suggested three payment methods [9] viz., payment for power delivered, payment for reserve allocated and price process for reserve power. This research focus only on the payment for power delivered scheme. In this method, the reserve price will be paid only for the used reserve power. The reserve price is therefore higher than the spot price. Revenue and cost can be calculated from

$$
\begin{aligned}
& \mathrm{RV}= \sum_{i=1}^{N} \sum_{t=1}^{T}\left(P_{i t} \cdot S P_{t}\right) \cdot X_{i t}+r \sum_{i=1}^{N} \sum_{t=1}^{T} R P_{t} \cdot R_{i t} \cdot X_{i t} \\
& \mathrm{TC}=\quad(1-r) \sum_{i=1}^{N} \sum_{t=1}^{T} F\left(P_{i t}\right) \cdot X_{i t}+r \sum_{i=1}^{N} \sum_{t=1}^{T} F\left(P_{i t}+R_{i t}\right) \cdot X_{i t} \\
&+S T \cdot X_{i t}
\end{aligned}
$$

The total operating cost, over the entire scheduling period is the sum of production cost and start-up/shutdown cost for all the units. Here, the shutdown cost is considered as equal to 0 for all units. The production cost of the scheduled units is given in a quadratic form

$$
\min C_{i t}\left(P_{i t}\right)=a_{i}+b_{i} P_{i t}+c_{i} P_{i t}^{2}
$$

Constraints

1. Load demand constraint

$$
\sum_{i=1}^{N} P_{i t} X_{i t} \leq P D \quad 1 \leq i \leq N
$$

2. Generator limits constraint

$$
P_{i}^{\min } \leq P_{i} \leq P_{i}^{\max } \quad 1 \leq i \leq N
$$

3. Spinning reserve

$$
1 \leq t \leq T \quad \text { constraint }
$$

$$
\sum_{i=1}^{N} R_{i t} X_{i t} \leq S R
$$

4. Minimum up/down time constraints

$$
i=1,2, \ldots . N
$$$$
i=1,2, \ldots . N
$$

Where, variables are defined as follows:-

$\begin{array}{ll}P F & \text { total profit of GENCOs } \\ R V & \text { total revenue of GENCOs } \\ T C & \text { total generation cost of GENCOs } \\ P_{\text {it }} & \text { real power output of } i^{\text {th }} \text { Generator } \\ P_{D t} & \text { forecasted system demand during hour } \mathrm{t} \\ \mathrm{P}_{i t} \text { max } & \text { maximum limit of unit } \mathrm{i} \text { during hour of } \mathrm{t} \\ \mathrm{P}_{i t}{ }_{\text {min }} & \text { minimum limit of unit } \mathrm{i} \text { during hour of } \mathrm{t} \\ S P_{t} & \text { forecasted market price at hour of } \mathrm{t} \\ T & \text { number of time Periods considered } \\ r & \text { probability of reserve power usage } \\ N & \text { no of generating units } \\ a_{i}, b_{i}, c_{i} & \text { cost co-efficient of the } i^{\text {th }} \text { generator } \\ G E N C O & \text { generation Company } \\ T R A N S C O & \text { transmission Company } \\ D I S C O & \text { distribution Company } \\ R_{i}(t) & \text { Reserve } i^{\text {th }} \text { generating unit during hour of } \mathrm{t} \\ \mathrm{SR}(t) & \text { spinning reserve during hour of } \mathrm{t} \\ X_{i t} & \text { unit status }\end{array}$

\section{SOLUTION METHODOLOGY}

\subsection{Lagrangian Relaxation Technique}

The Lagrangian relaxation technique is a mathematical tool for mixed-integer programming problem. It aims to solve the PBUC problem by relaxing the coupling constraints. Consider the following primal optimization problem:

\section{Minimize $f(x)$}

Subject to

$$
h(x) \leqslant 0
$$

By adding the Lagrangian multiplier $\lambda$ with coupling constraints, the Lagrangian is framed as:

$$
\text { Minimize } L(x, \lambda)=f(x)+\lambda \cdot h(x)
$$

Now the problem becomes simple to solve. Once the proper value of $\lambda$ is chosen, then the constraints are relaxed and offer the best solution. It is important to note that the maximization objective function is equivalent to the minimization of modified objective function. So it can be specified as follows

$$
\text { Minimize } \sum_{i=1}^{n} \sum_{t=1}^{T}\left(-P F_{i t}\right)
$$

The profit based Lagrangian function is formed by assigning the multiplier $\lambda$ and $\mu$ to the constraints (5) and (7) respectively. Now the Lagrangian function becomes

$L(P, R, \lambda, \mu)=T C-R V-\sum_{t=1}^{T} \lambda_{t}\left(D_{t}^{`}-\sum_{i=1}^{N} P_{i t} . X_{i t}\right)-$

By assigning the $\sum_{t=1}^{T} \mu_{t}\left(S R_{t}^{\prime}-\sum_{i=1}^{N} R_{i t} \cdot X_{i t}\right) \quad$ total generation cost $t=1$ 


$$
\begin{aligned}
L=(1-r) \sum_{i=1}^{N} \sum_{t=1}^{T} F\left(P_{i t}\right) \cdot X_{i t}+r \sum_{i=1}^{N} \sum_{t=1}^{T} F\left(P_{i t}+R_{i t}\right) \cdot X_{i t} \\
+S T \cdot X_{i t}-\sum_{i=1}^{N} \sum_{t=1}^{T}\left(P_{i t} \cdot S P_{t}\right) \cdot X_{i t}-\sum_{i=1}^{N} \sum_{t=1}^{T} r \cdot\left(R P_{t} \cdot R_{i t}\right) \cdot X_{i t} \\
-\sum_{t=1}^{T} \lambda_{t}\left(D_{t} \cdot \sum_{i=1}^{N} P_{i t} \cdot X_{i t}\right)-\sum_{t=1}^{T} \mu_{t}\left(S R_{t}^{\prime}-\sum_{i=1}^{N} R_{i t} \cdot X_{i t}\right)
\end{aligned}
$$

After simplification

$$
\begin{array}{r}
L=\sum_{i=1}^{N} \sum_{t=1}^{T}\left[(1-r) F\left(P_{i t}\right)+r F\left(P_{i t}+R_{i t}\right)+S T-P_{i t}\right. \\
\left.. S P_{t}-r . R P_{t} \cdot R_{i t}\right] . X_{i t}+\sum_{i=1}^{N} \sum_{t=1}^{T}\left(r P_{i t}+\mu_{t} R_{i t}\right) \\
. X_{i t}-\sum_{t=1}^{T}\left(r D_{t}+\mu_{t} S R_{t}\right) \cdot X_{i t}
\end{array}
$$

The terms $r, D_{t}, \mu_{\mathrm{t}}$ and $S R_{t}$ are seems to be constant and can be ignored. Therefore the final Lagrangian function is written as

$$
\begin{aligned}
L= & \sum_{i=1}^{N}\left[\sum _ { t = 1 } ^ { T } \left\{(1-r) F\left(P_{i t}\right)+r F\left(P_{i t}+R_{i t}\right)+S T\right.\right. \\
& \left.\left.-P_{i t} . S P_{t}-r \cdot R P_{t} . R_{i t}+\lambda_{t} P_{i t}+\mu_{t} R_{i t}\right\} . X_{i t}\right]
\end{aligned}
$$

The above equation can be solved individually for each generating units irrespective of generation in other units. The least value of Lagrangian function is determined by solving for the minimum cost of each generating unit during the scheduling period.

$$
\begin{aligned}
& \min q(\lambda, \mu)=\sum_{i=1}^{N} \min \sum_{t=1}^{T}\left[(1-r) F\left(P_{i t}\right)\right. \\
& +r F\left(P_{i t}+R_{i t}\right)+S T_{t}-P_{i t} . S P_{t} \\
& \left.\quad-r . R P_{t} . R_{i t}+\lambda_{t} P_{i t}+\mu_{t} R_{i t}\right] . X_{i t}
\end{aligned}
$$

Subject to satisfying the constraints given in equation (5) $-(8)$.

\subsection{Dynamic Programming based Unit Commitment Scheduling.}

A forward dynamic programming method is used to solve the dual problem. The objective of this problem is to minimize the dual function $\boldsymbol{q}$, along with the minimum up and down time constraints of the generators. Also the initial status of the generators must be taken in to account. The dual function $\boldsymbol{q}$ becomes zero, when all the generators are in OFF state. In order to make the problem to be simple, the function $\mathrm{K}$ is introduced for each individual unit during the $\mathrm{ON}$ state of generators.

$$
\begin{array}{r}
K=(1-r) F\left(P_{i t}\right)+r F\left(P_{i t}+R_{i t}\right)- \\
\boldsymbol{P}_{i t} \cdot \boldsymbol{S P}_{t}-r \cdot R P_{t} \cdot R_{i t}+\lambda_{t} P_{i t}+\mu_{t} R_{i t}
\end{array}
$$

The minimum value of this function is obtained by finding the first derivative of $K$ with respect to power $P_{i t}$, reserves $R_{i t}$ and made it to zero.

$$
\begin{aligned}
& \frac{\partial K}{\partial P_{i t}}=0 \\
& \frac{\partial K}{\partial R_{i t}}=0
\end{aligned}
$$

The above equation is simplified, and given in matrix form are as follows

$$
\left[\begin{array}{l}
P_{i t} \\
R_{i t}
\end{array}\right]=\frac{1}{1-r}\left[\begin{array}{cc}
1 & -r \\
-1 & 1
\end{array}\right]\left[\begin{array}{l}
A_{i t} \\
B_{i t}
\end{array}\right]
$$

$$
\begin{aligned}
A_{i t} & =\frac{S P_{t}-\lambda_{t}-b_{i}}{2 c i} \\
B_{i t} & =\frac{\left(\frac{r \cdot R P_{t}-\mu_{i}}{r}-b_{i}\right)}{2 c_{i}}
\end{aligned}
$$

Finally, the value of dual function $q$ is calculated from the equation (16) by substituting the above values.

\subsection{Updating Lagrange Multipliers Using Quantum Inspired Particle Swarm Optimization}

The identification and selection of best Lagrange multipliers is accomplished by using Quantum inspired PSO, so as to minimize the dual function $q(\lambda, \mu)$.

The Quantum inspired particle swarm optimization (QPSO) is one of the recent optimization technique introduced by Sun in 2004 [24-25] which is based on quantum mechanics. Like any other evolutionary algorithm, a quantum inspired particle swarm algorithm relies on the representation of the individual, the evolutionary function and the population dynamics. The 
particularity of quantum particle swarm algorithm stems from the quantum representation it adopts which allows the superposition of all potential solutions for a given problem. QPSO has stronger search ability and quicker convergence speed since it not only introduces the concepts of quantum bit and rotation gate but also the implementation of self-adaptive probability selection and chaotic sequence mutation.

Definition of quantum bit, the smallest unit in the QPSO, is defined as a pair of numbers

$$
\left[\begin{array}{l}
\alpha_{j t}(t) \\
\beta_{j t}(t)
\end{array}\right] \quad\left\{\begin{array}{l}
j=1,2 \ldots ., m \\
i=1,2 \ldots . ., n
\end{array}\right.
$$

The modulus $\left|\alpha_{j i}(t)\right|^{2}$ and $\left|\beta_{j i}(t)\right|^{2}$ give the probabilities that the quantum bit exists in states " 0 " and " 1 ", respectively, which must satisfy

$$
\left|\alpha_{j i}(t)\right|^{2}+\left|\beta_{j i}(t)\right|^{2}=1
$$

A string of quantum bits consists of quantum bit individual, which can be defined as

$$
\begin{aligned}
& q_{j}(t)=\left[\begin{array}{l}
\alpha_{q l}(t), \ldots, \alpha_{j i}(t), \ldots ., \alpha_{j n}(t) \\
\beta_{j l}(t), \ldots, \beta_{j i}(t), \ldots, \beta_{j n}(t)
\end{array}\right] \\
& =\left[q_{j l}(t), \ldots \ldots, q_{j i}(t), \ldots . ., q_{j n}(t)\right]
\end{aligned}
$$

A quantum bit is able to represent a linear superposition of all possible solutions due to its probabilistic representation. As a result, totally $2 \mathrm{n}$ kinds of individual can be represented by combination of different quantum bit states. This quantum bit representation has better characteristic of generating diversity in population than other representations. The quantum bit individual can be represented in the form of quantum angles.

$$
\begin{aligned}
& q_{j}(t)=\left[q_{j l}(t), \ldots, q_{j i}(t), \ldots, q_{j n}(t)\right] \\
& \theta_{j}(t)=\left[\theta_{j l}(t), \ldots, \theta_{j i}(t), \ldots, \theta_{j n}(t)\right]
\end{aligned}
$$

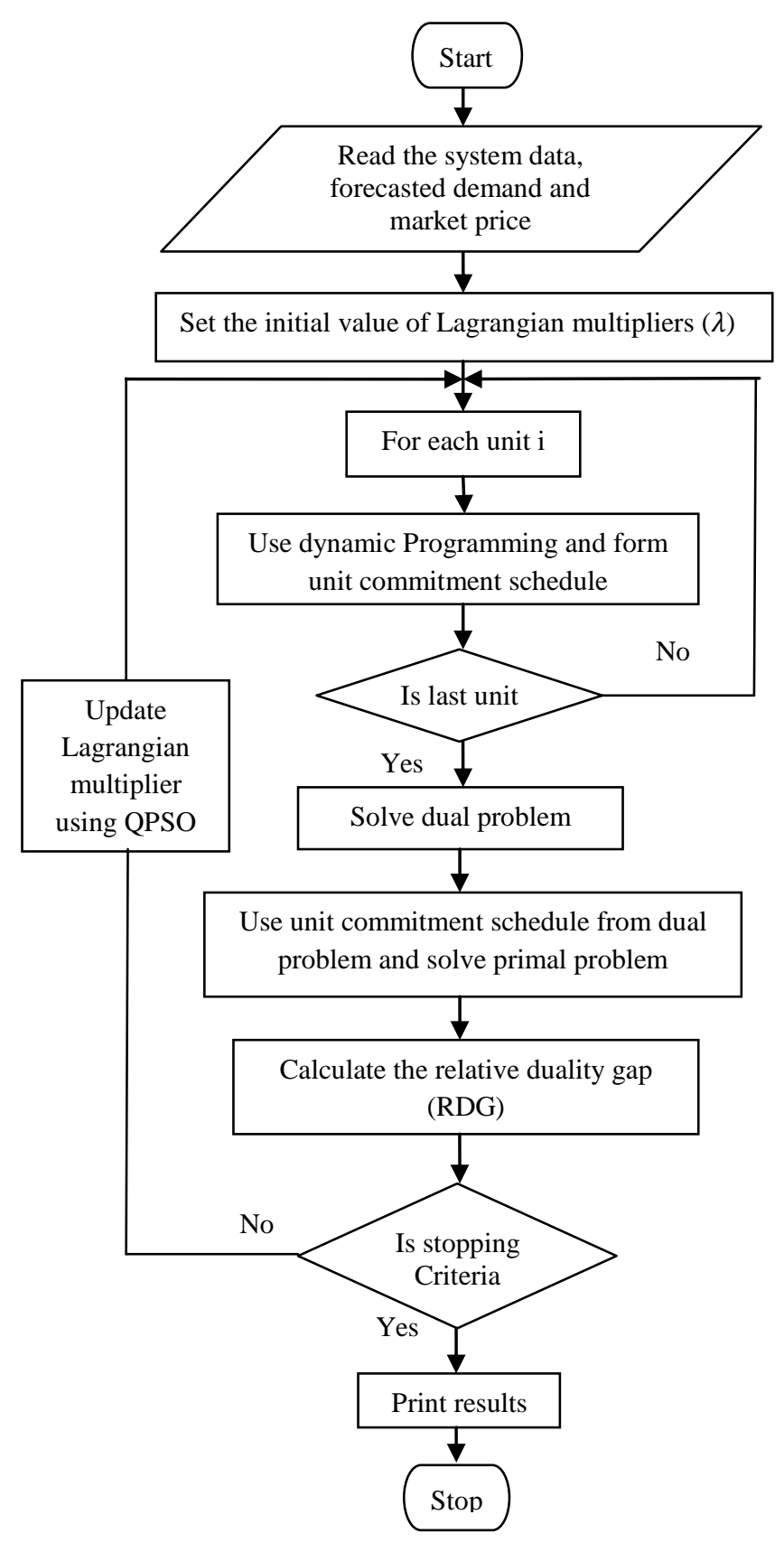

Fig.1.Flow chart for proposed method

\subsubsection{Updating particles:}

The main idea of QPSO is to update the particle position represented as a quantum angle $\theta$. The common velocity update equation in conventional PSO is modified to get a new quantum angle which is translated to the new probability of the Qbit by using the following formula.

$$
\begin{array}{r}
\Delta \theta_{j q}^{t+1}=\omega \times \Delta \theta_{j q}^{t} \\
+C_{1} \cdot \operatorname{rand} 1 .\left(\theta_{b j q}-\theta_{j q}^{t}\right) \\
+C_{2} \cdot \operatorname{rand} 2 .\left(\theta_{g q}-\theta_{j q}^{t}\right)
\end{array}
$$


Where,
$\Delta \theta_{j q}^{t}$
angle changes of $q^{\text {th }}$ dimension of $j^{\text {th }}$ particle
$\omega$
inertia weight
$\mathrm{C}_{1}, \mathrm{C}_{2}$
acceleration factors
rand1, rand2
random numbers from 0 to 1
$\theta_{b j q} \quad$ local best angles
$\theta_{g q}$
global best angles of $\mathrm{q}^{\text {th }}$ dimension

According to the angle changes, the matrix expression of the quantum rotation gate can be described by

$$
\left[\begin{array}{l}
\cos \Delta \theta_{j q}^{t+1}-\sin \Delta \theta_{j q}^{t+1} \\
\sin \Delta \theta_{j q}^{t+1}+\cos \Delta \theta_{j q}^{t+1}
\end{array}\right]
$$

Where $\Delta \theta_{j q}{ }^{t+1}$ denotes angle changes of qth dimension of $j^{\text {th }}$ particle in the $\mathrm{t}+1^{\text {th }}$ iterative course; In the next step, probability amplitudes of $q^{\text {th }}$ dimension of $j^{\text {th }}$ particle in $\mathrm{t}+1^{\text {th }}$ iterative course can be updated according rotation gate.

\subsection{Terminating Criteria}

In this paper, the difference between primal and dual problem (duality gap) is used as a terminating criteria. Duality gap is defined as

$$
\varepsilon=\frac{J-q}{|J|}
$$

\section{SIMULATION AND RESULTS COMPARISON}

The validity of QPSO based PBUC problem is evaluated by implementing on two test systems.

Table 1. Unit data for three unit system

\begin{tabular}{l|c|c|c}
\hline & Unit-1 & Unit-2 & Unit-3 \\
\hline Pmax $(\mathrm{MW})$ & 600 & 400 & 200 \\
\hline Pmin $(\mathrm{MW})$ & 100 & 100 & 50 \\
\hline $\mathrm{a}(\$ / \mathrm{h})$ & 500 & 300 & 100 \\
\hline $\mathrm{b}(\$ / \mathrm{MWh})$ & 10 & 8 & 6 \\
\hline $\mathrm{c}\left(\$ / \mathrm{MW}^{2} \mathrm{~h}\right)$ & 0.002 & 0.0025 & 0.005 \\
\hline Min up time(h) & 3 & 3 & 3 \\
\hline Min down time $(\mathrm{h})$ & 3 & 3 & 3 \\
\hline Startup cost $(\$)$ & 450 & 400 & 300 \\
\hline Initial status(h) & -3 & 3 & 3
\end{tabular}

\subsection{Test case: 1 (Three unit Test System)}

This test system adapted from [23] consisting of three generating units with twelve hour scheduling periods and the fuel cost of each generators is estimated into quadratic form. The generator data, forecasted market and demand price are also considered from the same reference. These data are described in Table-1 and Table-2.

The feasible parameters obtained by various processes for QPSO are as follows. Population size $=40$; Acceleration Coefficients are 0.5 and 1.25 respectively. Inertia weight $\omega=$ 0.72 and maximum number of iterations $=500$.

Table -IV compares the power and reserve generations of traditional and PBUC systems for three unit Twelve hour system. From this table, it is observed that the GENCO decides to shut off Unit 1 in all the commitment period and to sell power and reserve below the forecasted level in some periods. This is because the objective of PBUC is not to minimize the costs as before, but to maximize the profit with relaxation of the demand fulfillment and constraint. So the maximum profit is achieved by operating only two units (unit 2 and unit 3) rather than all the three units. Any have in the traditional method demand and reserve constraints must be satisfied.

Table 2. Forecasted demand and market prices

\begin{tabular}{c|c|c|c}
\hline $\begin{array}{c}\text { Hour } \\
(\mathrm{h})\end{array}$ & $\begin{array}{c}\text { Forecasted } \\
\text { Demand } \\
(\mathrm{MW})\end{array}$ & $\begin{array}{c}\text { Forecasted } \\
\text { Reserve } \\
(\mathrm{MW})\end{array}$ & $\begin{array}{c}\text { Forecasted } \\
\text { market Price } \\
(\$ / \mathrm{MW}-\mathrm{h})\end{array}$ \\
\hline 1 & 170 & 20 & 10.55 \\
\hline 2 & 250 & 25 & 10.35 \\
\hline 3 & 400 & 40 & 9.00 \\
\hline 4 & 520 & 55 & 9.45 \\
\hline 5 & 700 & 70 & 10.00 \\
\hline 6 & 1050 & 95 & 11.25 \\
\hline 7 & 1100 & 100 & 11.30 \\
\hline 8 & 800 & 80 & 10.65 \\
\hline 9 & 650 & 65 & 10.35 \\
\hline 10 & 330 & 35 & 11.20 \\
\hline 11 & 400 & 40 & 10.75 \\
\hline 12 & 550 & 55 & 10.60 \\
\hline
\end{tabular}

Table 3. Unit commitment scheduling for 3 unit 12 Hour system

Hour (h)

\begin{tabular}{c|c|c|c|c|c|c|c|c|c|c|c|c}
\hline Unit & 1 & 2 & 3 & 4 & 5 & 6 & 7 & 8 & 9 & 10 & 11 & 12 \\
\hline 1 & 0 & 0 & 0 & 0 & 0 & 0 & 0 & 0 & 0 & 0 & 0 & 0 \\
\hline 2 & 0 & 0 & 0 & 0 & 1 & 1 & 1 & 1 & 1 & 1 & 1 & 1 \\
\hline 3 & 1 & 1 & 1 & 1 & 1 & 1 & 1 & 1 & 1 & 1 & 1 & 1 \\
\hline
\end{tabular}


Table 4. Comparison of power and reserve generation of traditional and profit based unit commitment for 3 unit 12 hour system $(r=0.05)$

\begin{tabular}{|c|c|c|c|c|c|c|c|c|c|c|c|c|}
\hline \multicolumn{7}{|c|}{ Traditional Unit Commitment } & \multicolumn{6}{|c|}{ Profit-based Unit Commitment } \\
\hline \multirow{2}{*}{$\begin{array}{c}\mathrm{H} \\
(\mathrm{hr})\end{array}$} & \multicolumn{3}{|c|}{ Power (MW) } & \multicolumn{3}{|c|}{ Reserve (MW) } & \multicolumn{3}{|c|}{ Power (MW) } & \multicolumn{3}{|c|}{ Reserve (MW) } \\
\hline & Unit 1 & Unit 2 & Unit 3 & Unit 1 & Unit 2 & Unit 3 & $\begin{array}{c}\text { Unit } \\
1\end{array}$ & Unit 2 & Unit 3 & Unit 1 & Unit 2 & Unit 3 \\
\hline 1 & 0 & 100 & 70 & 0 & 0 & 20 & 0 & 0 & 170 & 0 & 0 & 20 \\
\hline 2 & 0 & 100 & 150 & 0 & 0 & 25 & 0 & 0 & 200 & 0 & 0 & 0 \\
\hline 3 & 0 & 200 & 200 & 0 & 40 & 0 & 0 & 0 & 200 & 0 & 0 & 0 \\
\hline 4 & 0 & 320 & 200 & 0 & 55 & 0 & 0 & 0 & 200 & 0 & 0 & 0 \\
\hline 5 & 100 & 400 & 200 & 70 & 0 & 0 & 0 & 400 & 200 & 0 & 20 & 0 \\
\hline 6 & 450 & 400 & 200 & 95 & 0 & 0 & 0 & 400 & 200 & 0 & 0 & 0 \\
\hline 7 & 500 & 400 & 200 & 100 & 0 & 0 & 0 & 400 & 200 & 0 & 0 & 0 \\
\hline 8 & 200 & 400 & 200 & 80 & 0 & 0 & 0 & 400 & 200 & 0 & 0 & 0 \\
\hline 9 & 100 & 350 & 200 & 15 & 50 & 0 & 0 & 400 & 200 & 0 & 0 & 0 \\
\hline 10 & 100 & 100 & 130 & 0 & 0 & 35 & 0 & 130 & 200 & 0 & 35 & 0 \\
\hline 11 & 100 & 100 & 200 & 0 & 40 & 0 & 0 & 200 & 200 & 0 & 40 & 0 \\
\hline 12 & 100 & 250 & 200 & 0 & 55 & 0 & 0 & 350 & 200 & 0 & 50 & 0 \\
\hline
\end{tabular}

\begin{tabular}{c|c|c|c|c|c}
\hline \multirow{2}{*}{$\begin{array}{c}\text { Hour } \\
(\mathrm{h})\end{array}$} & \multirow{2}{*}{$\begin{array}{c}\text { Power } \\
\text { Demand }\end{array}$} & \multirow{2}{*}{$\begin{array}{c}\text { Revenue } \\
(\$ / \mathrm{MWh})\end{array}$} & \multirow{2}{*}{$\begin{array}{c}\text { Total generation } \\
\text { cost } \\
\end{array}$} & & \multicolumn{2}{|c}{ Profit $(\$)$} & $\begin{array}{c}\text { Conventional } \\
\text { method }\end{array}$ & $\begin{array}{c}\text { Proposed } \\
\text { method }\end{array}$ \\
\hline 1 & 170 & 1793.50 & 1263.50 & 126.50 & 530.00 \\
\hline 2 & 250 & 2070 & 1500 & 352.90 & 570.00 \\
\hline 3 & 400 & 1800 & 1500 & 103.60 & 300.00 \\
\hline 4 & 720 & 1890 & 1500 & 303.10 & 390.00 \\
\hline 5 & 700 & 6000 & 5400 & -363.20 & 600.00 \\
\hline 6 & 1050 & 6750 & 5400 & 1017.80 & 1350.00 \\
\hline 7 & 1100 & 6780 & 5400 & 1040.90 & 1380.00 \\
\hline 8 & 800 & 6390 & 5400 & 548.40 & 990.00 \\
\hline 9 & 650 & 6210 & 5400 & 308.10 & 810.00 \\
\hline 10 & 330 & 3696 & 2882.25 & 91.10 & 813.75 \\
\hline 11 & 400 & 4500 & 3500 & 159.70 & 800.00 \\
\hline 12 & 550 & 5830 & 4906.25 & 359.90 & 923.75 \\
\hline & & & Total profit & $\mathbf{4 0 4 8 . 8 0}$ & $\mathbf{9 4 5 7 . 5 0}$ \\
\hline
\end{tabular}

Table 5. Simulation results for 3 unit 12 hour system

Table 6. Comparison of proposed method with the existing methods

\begin{tabular}{c|c}
\hline Method & Profit(\$) \\
\hline LR-gradient search [5] & 8672.35 \\
\hline Muller method [5] & 9056.49 \\
\hline LR-EP [23] & 9074.30 \\
\hline LR-QPSO(Proposed method) & $\mathbf{9 4 5 7 . 5 0}$ \\
\hline
\end{tabular}




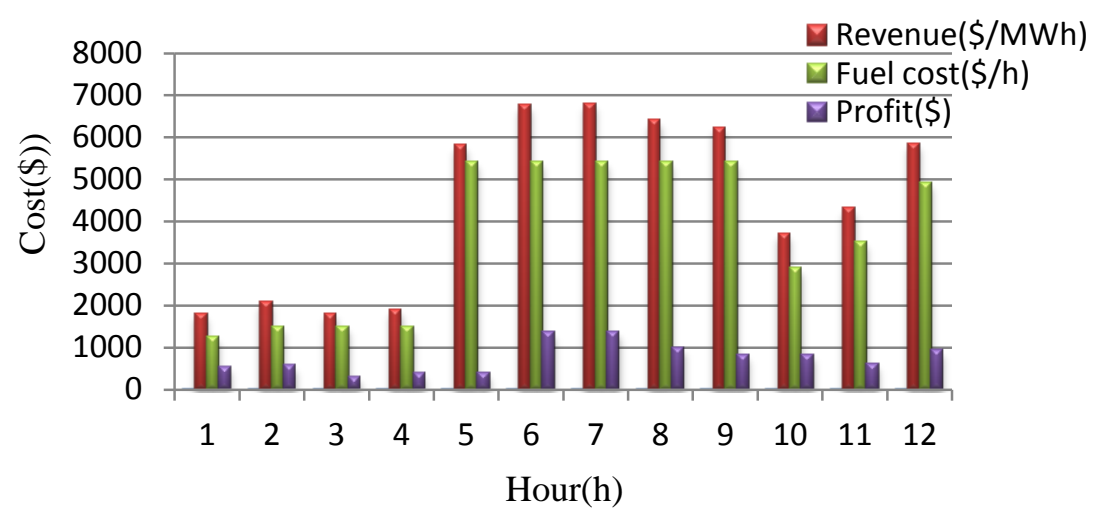

Fig 2: Revenue, fuel cost and profit for three unit 12 our system

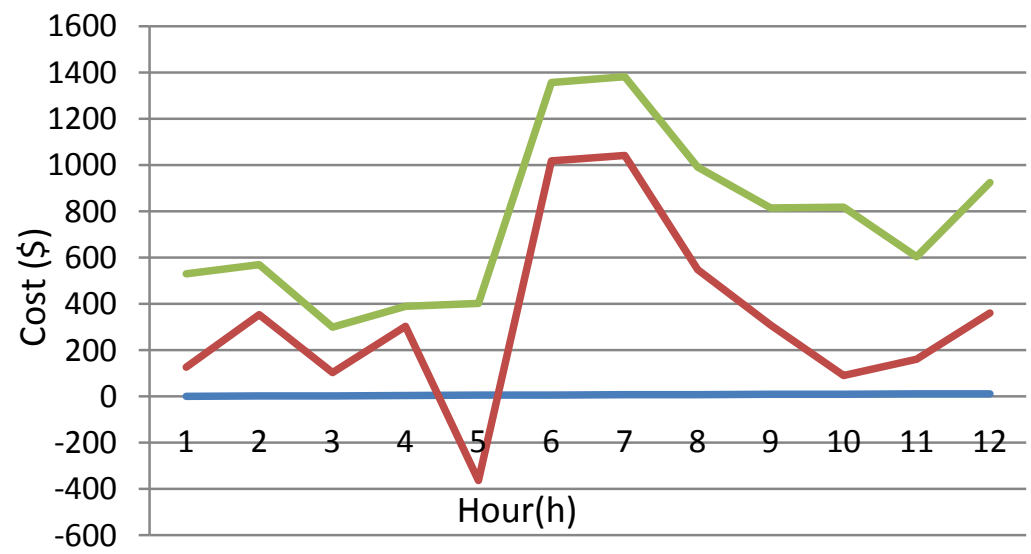

Fig 3: Comparison of profits of the proposed and conventional method for three unit 12 hour system

Table 7. Unit data for ten unit system

\begin{tabular}{c|c|c|c|c|c|c|c|c|c|c}
\hline & Unit 1 & Unit 2 & Unit 3 & Unit 4 & Unit 5 & Unit 6 & Unit 7 & Unit 8 & Unit 9 & Unit 10 \\
\hline $\mathrm{P}_{\max }$ & 455 & 455 & 130 & 130 & 162 & 80 & 85 & 55 & 55 & 55 \\
\hline $\mathrm{P}_{\min }$ & 150 & 150 & 20 & 20 & 25 & 20 & 25 & 10 & 10 & 10 \\
\hline $\mathrm{a}$ & 0.00048 & 0.00031 & 0.20200 & 0.00211 & 0.00398 & 0.20712 & 0.00079 & 0.20413 & 0.00222 & 0.00173 \\
\hline $\mathrm{b}$ & 16.19 & 17.26 & 16.60 & 16.50 & 19.70 & 22.26 & 27.74 & 25.92 & 27.27 & 27.79 \\
\hline $\mathrm{c}$ & 1000 & 970 & 700 & 680 & 450 & 370 & 480 & 660 & 665 & 670 \\
\hline Min up & 8 & 8 & 5 & 5 & 6 & 3 & 3 & 1 & 1 & 1 \\
\hline Min down & 8 & 8 & 5 & 5 & 6 & 3 & 3 & 1 & 1 & 1 \\
\hline ST & 4500 & 5000 & 550 & 560 & 900 & 170 & 260 & 30 & 30 & 30 \\
\hline Initial & 8 & 8 & -5 & -5 & -6 & -3 & -3 & -1 & -1 & -1 \\
\hline
\end{tabular}


Table 8. Forecasted demand and spot price for ten unit 24 hour system

\begin{tabular}{|c|c|c|c|}
\hline $\begin{array}{l}\text { Hour } \\
\text { (h) }\end{array}$ & $\begin{array}{c}\text { Forecasted } \\
\text { Demand } \\
(\mathrm{MW})\end{array}$ & $\begin{array}{c}\text { Forecasted } \\
\text { Reserve } \\
\text { (MW) }\end{array}$ & $\begin{array}{c}\text { Forecasted } \\
\text { Market price } \\
(\$ / \mathrm{MWh})\end{array}$ \\
\hline 1 & 700 & 70 & 22.15 \\
\hline 2 & 750 & 75 & 22.00 \\
\hline 3 & 850 & 85 & 23.10 \\
\hline 4 & 950 & 95 & 23.65 \\
\hline 5 & 1000 & 100 & 22.25 \\
\hline 6 & 1100 & 110 & 22.95 \\
\hline 7 & 1150 & 115 & 22.50 \\
\hline 8 & 1200 & 120 & 22.15 \\
\hline 9 & 1300 & 130 & 22.80 \\
\hline 10 & 1400 & 140 & 29.35 \\
\hline 11 & 1450 & 145 & 30.15 \\
\hline 12 & 1500 & 150 & 31.65 \\
\hline 13 & 1400 & 140 & 24.60 \\
\hline 14 & 1300 & 130 & 24.50 \\
\hline 15 & 1200 & 120 & 22.50 \\
\hline 16 & 1050 & 105 & 22.30 \\
\hline 17 & 1000 & 100 & 22.25 \\
\hline 18 & 1100 & 110 & 22.05 \\
\hline 19 & 1200 & 120 & 22.20 \\
\hline 20 & 1400 & 140 & 22.65 \\
\hline 21 & 1300 & 130 & 23.10 \\
\hline 22 & 1100 & 110 & 22.95 \\
\hline 23 & 900 & 90 & 22.75 \\
\hline 24 & 800 & 80 & 22.55 \\
\hline
\end{tabular}

Table 9. Unit commitment scheduling for 10 unit 24 hour system Hour (h)

\begin{tabular}{c|c|c|c|c|c|c|c|c|c|c|c|c|c|c|c|c|c|c|c|c|c|c|c|c}
\hline Unit & 1 & 2 & 3 & 4 & 5 & 6 & 7 & 8 & 9 & 10 & 11 & 12 & 13 & 14 & 15 & 16 & 17 & 18 & 19 & 20 & 21 & 22 & 23 & 24 \\
\hline 1 & 1 & 1 & 1 & 1 & 1 & 1 & 1 & 1 & 1 & 1 & 1 & 1 & 1 & 1 & 1 & 1 & 1 & 1 & 1 & 1 & 1 & 1 & 1 & 1 \\
\hline 2 & 1 & 1 & 1 & 1 & 1 & 1 & 1 & 1 & 1 & 1 & 1 & 1 & 1 & 1 & 1 & 1 & 1 & 1 & 1 & 1 & 1 & 1 & 1 & 1 \\
\hline 3 & 0 & 0 & 0 & 0 & 1 & 1 & 1 & 1 & 1 & 1 & 1 & 1 & 1 & 1 & 1 & 1 & 1 & 1 & 1 & 1 & 1 & 1 & 0 & 0 \\
\hline 4 & 0 & 0 & 0 & 0 & 0 & 0 & 0 & 0 & 1 & 1 & 1 & 1 & 1 & 1 & 0 & 0 & 0 & 0 & 0 & 1 & 1 & 0 & 0 & 0 \\
\hline 5 & 0 & 0 & 0 & 0 & 0 & 0 & 0 & 0 & 1 & 1 & 1 & 1 & 1 & 1 & 0 & 0 & 0 & 0 & 0 & 1 & 1 & 0 & 0 & 0 \\
\hline 6 & 0 & 0 & 0 & 0 & 0 & 0 & 0 & 0 & 0 & 1 & 1 & 1 & 1 & 0 & 0 & 0 & 0 & 0 & 0 & 1 & 0 & 0 & 0 & 0 \\
\hline 7 & 0 & 0 & 0 & 0 & 0 & 0 & 0 & 0 & 0 & 0 & 0 & 0 & 0 & 0 & 0 & 0 & 0 & 0 & 0 & 0 & 0 & 0 & 0 & 0 \\
\hline 8 & 0 & 0 & 0 & 0 & 0 & 0 & 0 & 0 & 0 & 0 & 0 & 0 & 0 & 0 & 0 & 0 & 0 & 0 & 0 & 0 & 0 & 0 & 0 & 0 \\
\hline 9 & 0 & 0 & 0 & 0 & 0 & 0 & 0 & 0 & 0 & 0 & 0 & 0 & 0 & 0 & 0 & 0 & 0 & 0 & 0 & 0 & 0 & 0 & 0 & 0 \\
\hline 10 & 0 & 0 & 0 & 0 & 0 & 0 & 0 & 0 & 0 & 0 & 0 & 0 & 0 & 0 & 0 & 0 & 0 & 0 & 0 & 0 & 0 & 0 & 0 & 0 \\
\hline
\end{tabular}


Table 10. Power and reserve generation of profit based unit commitment for 10 unit 24 hour system $(r=0.05)$

\begin{tabular}{|c|c|c|c|c|c|c|c|c|c|c|c|c|c|c|c|c|c|c|c|c|c|}
\hline \multirow{2}{*}{$\begin{array}{c}\mathrm{H} \\
\text { (h) } \\
\end{array}$} & \multirow{2}{*}{$\begin{array}{c}\mathrm{P}_{\mathrm{D}} \\
(\mathrm{MW})\end{array}$} & \multicolumn{10}{|c|}{ Generation power (MW) } & \multicolumn{10}{|c|}{ Reserve power (MW) } \\
\hline & & $\mathrm{P} 1$ & $\mathrm{P} 2$ & P3 & $\mathrm{P} 4$ & P5 & P6 & $\mathrm{P7}$ & P8 & $\mathrm{P} 9$ & P10 & $\mathrm{R} 1$ & $\mathrm{R} 2$ & R3 & $\mathrm{R} 4$ & R5 & R6 & R7 & R8 & R9 & $\mathrm{R} 10$ \\
\hline 1 & 700 & 455 & 245 & 0 & 0 & 0 & 0 & 0 & 0 & 0 & 0 & 0 & 70 & 0 & 0 & 0 & 0 & 0 & 0 & 0 & 0 \\
\hline 2 & 750 & 455 & 295 & 0 & 0 & 0 & 0 & 0 & 0 & 0 & 0 & 0 & 70 & 0 & 0 & 0 & 0 & 0 & 0 & 0 & 0 \\
\hline 4 & 950 & 455 & 455 & 0 & 0 & 0 & 0 & 0 & 0 & 0 & 0 & 0 & 56 & 0 & 0 & 0 & 0 & 0 & 0 & 0 & 0 \\
\hline 5 & 1000 & 455 & 415 & 130 & 0 & 0 & 0 & 0 & 0 & 0 & 0 & 0 & 40 & 0 & 0 & 0 & 0 & 0 & 0 & 0 & 0 \\
\hline 6 & 1100 & 455 & 455 & 130 & 0 & 0 & 0 & 0 & 0 & 0 & 0 & 0 & 0 & 0 & 0 & 0 & 0 & 0 & 0 & 0 & 0 \\
\hline 8 & 1200 & 455 & 455 & 130 & 0 & 0 & 0 & 0 & 0 & 0 & 0 & 0 & 0 & 0 & 0 & 0 & 0 & 0 & 0 & 0 & 0 \\
\hline 9 & 1300 & 455 & 455 & 130 & 130 & 130 & 0 & 0 & 0 & 0 & 0 & 0 & 0 & 0 & 0 & 32 & 0 & 0 & 0 & 0 & 0 \\
\hline 10 & 1400 & 455 & 455 & 130 & 130 & 162 & 68 & 0 & 0 & 0 & 0 & 0 & 0 & 0 & 0 & 0 & 12 & 0 & 0 & 0 & 0 \\
\hline 11 & 1450 & 455 & 455 & 130 & 130 & 162 & 80 & 0 & 0 & 0 & 0 & 0 & 0 & 0 & 0 & 0 & 0 & 0 & 0 & 0 & 0 \\
\hline 12 & 1500 & 455 & 455 & 130 & 130 & 162 & 80 & 0 & 0 & 0 & 0 & 0 & 0 & 0 & 0 & 0 & 0 & 0 & 0 & 0 & 0 \\
\hline 13 & 1400 & 455 & 455 & 130 & 130 & 162 & 68 & 0 & 0 & 0 & 0 & 0 & 0 & 0 & 0 & 0 & 12 & 0 & 0 & 0 & 0 \\
\hline 18 & 1100 & 455 & 455 & 130 & 0 & 0 & 0 & 0 & 0 & 0 & 0 & 0 & 0 & 0 & 0 & 0 & 0 & 0 & 0 & 0 & 0 \\
\hline 19 & 1200 & 455 & 455 & 130 & 0 & 0 & 0 & 0 & 0 & 0 & 0 & 0 & 0 & 0 & 0 & 0 & 0 & 0 & 0 & 0 & 0 \\
\hline 20 & 1400 & 455 & 455 & 130 & 130 & 162 & 68 & 0 & 0 & 0 & 0 & 0 & 0 & 0 & 0 & 0 & 12 & 0 & 0 & 0 & 0 \\
\hline 21 & 1300 & 455 & 455 & 130 & 130 & 130 & 0 & 0 & 0 & 0 & 0 & 0 & 0 & 0 & 0 & 32 & 0 & 0 & 0 & 0 & 0 \\
\hline 22 & 1100 & 455 & 455 & 130 & 0 & 0 & 0 & 0 & 0 & 0 & 0 & 0 & 0 & 0 & 0 & 0 & 0 & 0 & 0 & 0 & 0 \\
\hline 23 & 900 & 455 & 445 & 0 & 0 & 0 & 0 & 0 & 0 & 0 & 0 & 0 & 10 & 0 & 0 & 0 & 0 & 0 & 0 & 0 & 0 \\
\hline 24 & 800 & 455 & 345 & 0 & 0 & 0 & 0 & 0 & 0 & 0 & 0 & 0 & 80 & 0 & 0 & 0 & 0 & 0 & 0 & 0 & 0 \\
\hline
\end{tabular}

Therefore the proposed LR - QPSO methodology is tested to demonstrate its performance on three units twelve hour system using MATLAB and the simulation results are presented in Table V. The graphical representation of revenue, fuel cost and profit are shown in fig-2, the profits of the conventional and proposed method are displayed in fig-3. For the purpose of comparison, the traditional method is also applied to solve the same PBUC problem. From the results, it is evident that the proposed method improves the profit of the GENCOs. Table VI shows the comparison of profits of existing optimizing methods with the proposed method.

\subsection{Test Case: 2 (Ten Unit Test System)}

In this example, Ten unit Twenty Four hour test system is considered and the unit data for the system is given in Table
VII. This table also describes the initial status of generators. Forecasted demand and spot price, commitment status of units, power and reserve generations of PBUC are given in Tables VIII, IX and $X$ respectively. The graphical representation of revenue, fuel cost and profit are shown in fig-4, the profits of the conventional and proposed method are displayed in fig-5. The simulation result shows that the proposed method performs well for larger systems also. Table XI exhibits the higher profits of QPSO technique when compared with the Traditional methods. The proposed QPSO technique is compared with that of existing optimizing techniques and is given in Table XII. It is clear that the profit obtained by the QPSO based technique ensures higher profit than other methods. 
Table 11. Simulation results for 10 unit 24 hour system

\begin{tabular}{|c|c|c|c|c|c|c|c|}
\hline \multirow{2}{*}{$\begin{array}{l}\mathrm{h} \\
\text { (h) }\end{array}$} & \multirow{2}{*}{$\begin{array}{c}\mathrm{P}_{\mathrm{D}} \\
(\mathrm{MW})\end{array}$} & \multicolumn{3}{|c|}{ Traditional unit commitment } & \multicolumn{3}{|c|}{ Profit based unit commitment(PBUC) } \\
\hline & & $\begin{array}{c}\text { Fuel cost } \\
\text { (\$) }\end{array}$ & $\begin{array}{c}\text { Revenue } \\
\text { (\$) }\end{array}$ & $\begin{array}{c}\text { Profit } \\
(\$)\end{array}$ & $\begin{array}{c}\text { Fuel } \\
\operatorname{cost}(\$)\end{array}$ & $\begin{array}{c}\text { Revenue } \\
(\$)\end{array}$ & $\begin{array}{c}\text { Profit } \\
(\$)\end{array}$ \\
\hline 1 & 700 & 13683 & 15505 & 1822 & 13683.00 & 15505 & 1822.00 \\
\hline 2 & 750 & 14554 & 16500 & 1946 & 14552.00 & 16500 & 1946.00 \\
\hline 3 & 850 & 16302 & 19635 & 3333 & 16301.90 & 19635 & 3333.10 \\
\hline 4 & 950 & 18625 & 20612 & 1647 & 21353.00 & 22995 & 1642.00 \\
\hline 5 & 1000 & 20469 & 21158 & 629 & 19512.77 & 23250 & 3737.23 \\
\hline 6 & 1100 & 22348 & 25245 & 697 & 24098.87 & 25245 & 1147.00 \\
\hline 7 & 1150 & 22755 & 25875 & 3120 & 22754.94 & 25875 & 3120.06 \\
\hline 8 & 1200 & 24150 & 25916 & -34 & 23105.56 & 25916 & 2810.44 \\
\hline 9 & 1300 & 26184 & 29640 & 3456 & 26184.00 & 29640 & 3456.00 \\
\hline 10 & 1400 & 28768 & 41090 & 11982 & 28768.21 & 41090 & 12321.79 \\
\hline 11 & 1450 & 30699 & 42572 & 11813 & 29047.66 & 42572 & 13524.34 \\
\hline 12 & 1500 & 32713 & 46431 & 13658 & 30896.00 & 46431 & 15535.00 \\
\hline 13 & 1400 & 28768 & 34440 & 5672 & 28768.00 & 34440 & 5672.00 \\
\hline 14 & 1300 & 26184 & 31850 & 5666 & 26183.75 & 31850 & 5666.00 \\
\hline 15 & 1200 & 24150 & 26325 & 2175 & 23105.32 & 26325 & 3219.68 \\
\hline 16 & 1050 & 21005 & 23415 & 2410 & 21213.96 & 23415 & 2201.04 \\
\hline 17 & 1000 & 20133 & 16799 & -3334 & 19512.77 & 22250 & 2737.23 \\
\hline 18 & 1100 & 21879 & 24255 & 2376 & 21878.12 & 24255 & 2376.88 \\
\hline 19 & 1200 & 23106 & 25974 & 2868 & 23105.58 & 25974 & 2868.42 \\
\hline 20 & 1400 & 31356 & 26501 & -5375 & 28768.00 & 31710 & 2942.00 \\
\hline 21 & 1300 & 27268 & 27027 & -241 & 26184.00 & 30030 & 3846.00 \\
\hline 22 & 1100 & 22348 & 25245 & 2897 & 21878.63 & 25245 & 3366.37 \\
\hline 23 & 900 & 17178 & 20475 & 3297 & 17177.90 & 20475 & 3297.10 \\
\hline 24 & 800 & 15427 & 18040 & 2613 & 15427.00 & 18040 & 2613.00 \\
\hline & \multicolumn{3}{|c|}{ Total profit (\$) } & 75093 & \multicolumn{2}{|c|}{ Total profit (\$) } & 105200.68 \\
\hline
\end{tabular}

Table 12. Comparison of proposed method with the existing methods

\begin{tabular}{c|c}
\hline Method & Profit(\$) \\
\hline TS-RP [6] & 101086.00 \\
\hline TS-TRP[16] & 103261.00 \\
\hline Muller method [15] & 103296.00 \\
\hline PSO [17] & 104356.00 \\
\hline PPSO [17] & 104556.23 \\
\hline LR-QPSO (Proposed method) & $\mathbf{1 0 5 2 0 0 . 6 8}$ \\
\hline
\end{tabular}




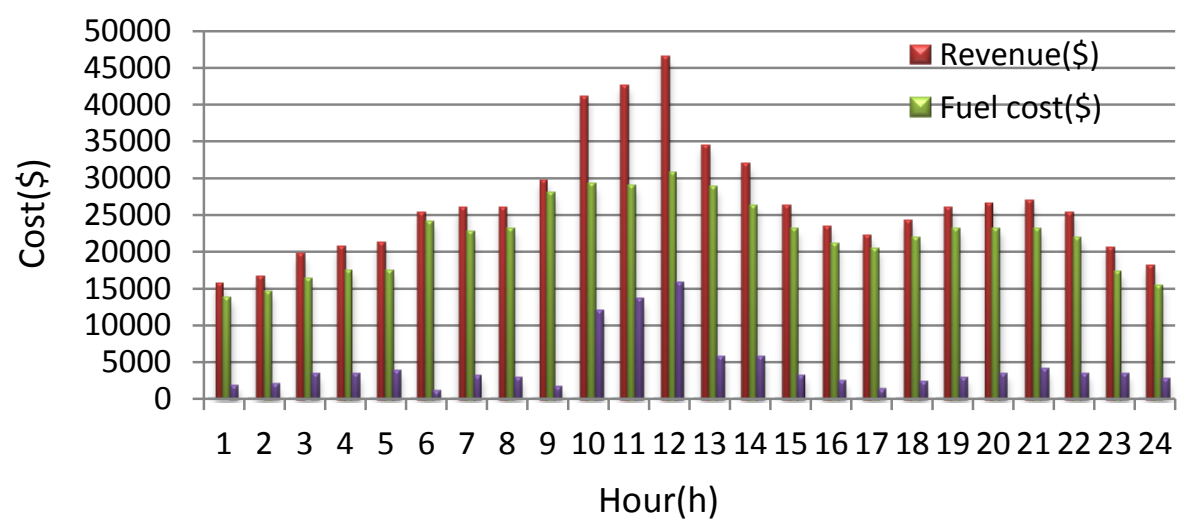

Fig 4: Revenue, Fuel cost and profit for the Ten unit 24 hour system

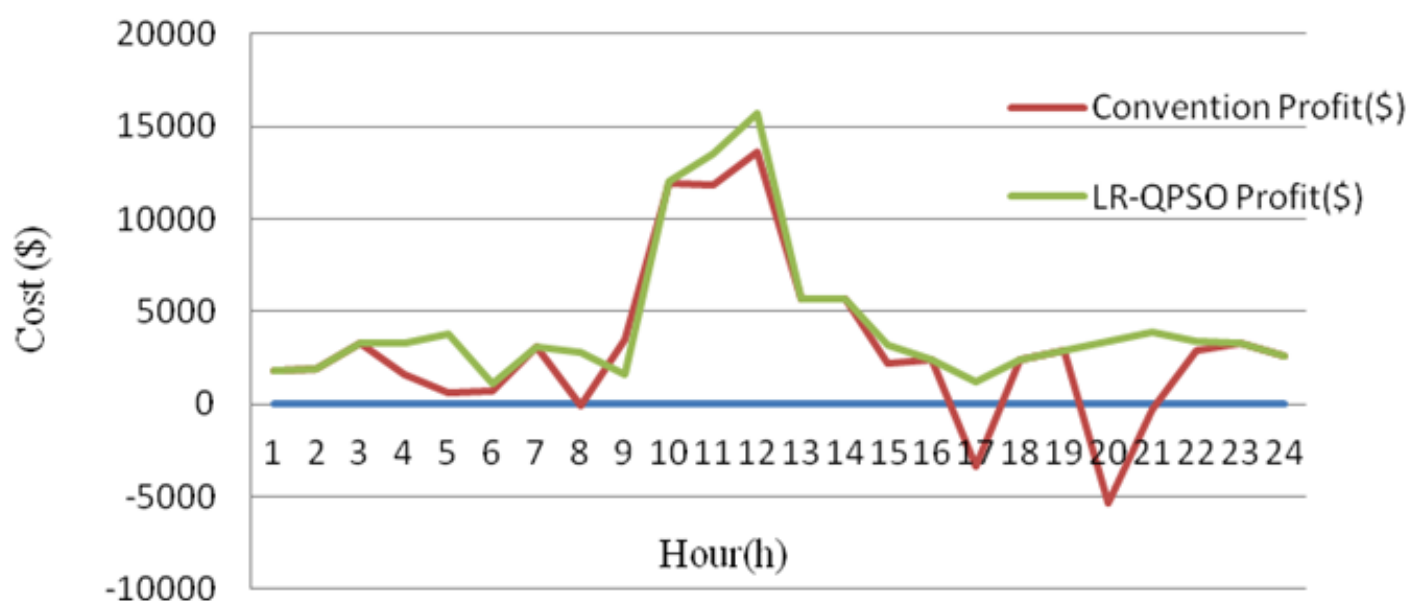

Fig 5: Comparison of profits of proposed and conventional method for ten unit 24 hour system

\section{CONCLUSION}

This paper presents a novel solution for profit based unit commitment problem (PBUC) in competitive electricity markets. A new optimization approach using Lagrangian relaxation combined with quantum inspired PSO (LR-QPSO) is proposed to solve the PBUC problem by considering the constraints such as load demand, spinning reserve, generated limits and minimum up and down time constraints. Two different size systems are used to determine the effectiveness of the proposed method for GENCOs.

The simulation result has been compared with conventional method, PSO, Muller method and hybrid methods such as TSRP, TR-IRP and LR-EP methods. The results obtained from the proposed method exhibit the maximization of profits over the other methods. This results show that LR-QPSO approach is a promising technique for solving complicated power system optimization problem under deregulated environment.

\section{ACKNOWLEDGEMENTS}

The authors gratefully acknowledge the authorities of Annamalai University for the facilities offered to carry out this work.

\section{REFERENCES}

[1] Mohammad Shahidehpour, H.Yamin, and Zuyili. 2002. Market Operations in Electric Power Systems Forecasting, Scheduling and Risk Management. New York: Wiley, Book.

[2] Mohammad Shahidehpour, Muwaffaq and Alomoush. 2000. Restructured electrical power systems, Operation, Trading, and volatility. New York: Wiley, Book.

[3] Mohammad Shahidehpour, Hatimyamin and salem, AIagtash. 2004. Security Constrained Optimal Generation Scheduling for GENCOs. IEEE Transactions on power systems, vol. 19, No.3, PP.1365-1371. 
[4] Narayana Prasad Padhy. 2004. Unit Commitment-A Bibliographical Survey. IEEE Transactions on power systems, Vol. 19, No. 2, pp.1196- 1205.

[5] Narayana Prasad Padhy. 2003. Unit commitment problem under deregulated environment- a review. Power Engineering Society General Meeting, Vol 2, PP. 1088-1094,

[6] Wood A. J. and Woolenberg B. F. 1996. Power generation, operation and control. New York, NY: John Wiley Sons; Book.

[7] Walter Snyder L, David Powell H. and John Rayburn C. 1987 Dynamic programming approach tounit commitment. IEEE Transactions on Power System, Vol. 2, No. 2, pp. 339-348.

[8] Cohen A. I. and Yoshimura M. 1983 A branch and bound algorithm for unit commitment. IEEE Transaction on Power Apparatus System, Vol. 102, No. 2, pp. 444451.

[9] Dillon T. S, Edwin K. W, Taud R. and Kochs H. D 1978. Integer programming approach to the problem of optimal unit commitment with probabilistic reserve Determination" IEEE Transaction on Power Apparatus System, Vol. 97, No. 6, pp. 2156-2166.

[10] Arroyo M. C. and Jose M. 2006. A computationally efficient mixed-integer linear formulation for the thermal unit commitment problem. IEEE Transactions on Power System, Vol. 21, No. 3, pp. 1371-348.

[11] Sudhir V., Adrian E. C., Imhof K. and Shishir M. 1989. Implementation of a Lagrangian based unit commitment problem. IEEE Transactions on Power System, Vol. 4, No. 4, pp. 1373-1380.

[12] Arroyo J. M. and Conejo A. J. 2002. A parallel repair genetic algorithm to solve the unit commitment problem. IEEE Transactions on Power System, Vol. 17, No. 4, pp. 1216-1224.

[13] C. W. Richter, Jr. and G. B. Sheble, 2000. A profitbased unit commitment for the competitive environment. IEEE Transactions on Power System, vol.15, pp. 715721.

[14] Dionisios K. Dimitroulas, Pavlos S. Georgilakis. 2011. A new memetic algorithm approach for the price based unit commitment problem. Applied Energy, Vol 88, Issue 12, pp 4687-4699.

[15] C.Christopher Columbus, K. Chandrasekaran, Sishaj P.Simon. 2012. Nodal ant colony optimization for solving profit based unit commitment problem for GENCOs. Applied soft computing, Vol. 12, PP. 145160.
[16] Jacob Raglend, C. Raghuveer, G. Rakesh Avinash, N.P. Padhy, D.P. Kothari . 2010. Solution to profit based unit commitment problem using particle swarm optimization. Applied Soft Computing Vol 10, Issue 4, pp. 1247-1256.

[17] C.Christopher Columbus and Sishaj P Simon. 2011 Profit based unit commitment for GENCOs using parallel PSO in a distributed cluster. ACEEE Int. J. on Electrical and Power Engineering, Vol. 02, No. 03.

[18] K. Chandram, N. Subrahmanyam, Member, IEEE, M.Sydulu.2008. New approach with Muller method for solving Profit Based Unit Commitment. DRPT2008 6-9 April 2008 Nanjing hina,952-957

[19] K. Chandram, N. Subrahmanyam and M. Sydulu. 2009. Improved Pre-prepared Power Demand Table and Muller's Method to Solve the Profit Based Unit Commitment Problem. Journal of Electrical Engineering \& Technology Vol. 4, No. 2, pp. 159-167.

[20] Tao Li, Member, IEEE, and Mohammad Shahidehpour, Fellow, IEEE. 2005. Price-Based Unit Commitment: A Case of Lagrangian Relaxation versus Mixed Integer Programming. IEEE Transactions on Power Systems, vol. 20 , no. 4, 2015-2025.

[21] Cheng C. P., Liu C.W. and Liu C. C. 2000. Unit commitment by Lagrangian relaxation and genetic algorithm. IEEE Transactions on Power System, Vol. 15, No. 2, pp. 707-714.

[22] H.Y.Yamin,Q.El-Dawirin,S.M.Shahidehpour. 2007. A new approach for GenCos Profit based unit commitment in day-ahead competitive electricity markets considering reserve uncertainty. Electrical power and energy systems, Vol. 29, PP. 609-616.

[23] Pathom attaviriyanupap, Hiroyuki kita,Jun Hasegawa. 2003. A Hybrid LR-EP for Solving New Profit-Based UC Problem under Competitive Environment. IEEE Transactions on power systems, Vol. 18, No. 1, PP. 229237.

[24] Zhang, Zhisheng. 2010. Quantum-behaved particle swarm optimization algorithm for economic load dispatch of power system. Expert system with application, Vol. 37, PP.1800 -1803.

[25] Chegfu Sun, Songfeng Lu. 2010. Short-term combined economic hydrothermal scheduling using improved quantum-behaved particle swarm optimization. Expert system with applications, Vol. 37, PP. 4232-4241. 